\title{
EFicÁcia de Herbicidas Aplicados em Diferentes Épocas sobre B. pilosa E I. quamoclit EM ÁREA DE CANA-DE-AçÚCAR ColHIDA MECANICAMENTE ${ }^{1}$
}

\author{
Effectiveness of Herbicides Applied at Different Times on B. pilosa and I. quamoclit in \\ Mechanically Harvested Sugarcane Area
}

MONQUERO, P.A. ${ }^{2}$, BINHA, D.P. ${ }^{3}$, INÁCIO, E.M. ${ }^{3}$, SILVA, P.V. ${ }^{3}$, AMARAL, L.R. ${ }^{3}$ e SILVA, A.C. ${ }^{4}$

\begin{abstract}
RESUMO - O objetivo deste trabalho foi estudar a eficácia agronômica de herbicidas utilizados em áreas no sistema da colheita da cana crua, visando o controle de Ipomoea quamoclit e Bidens pilosa em lavoura comercial de cana-soca, com solo de textura argilosa, no municipio de Araras-SP. Os herbicidas (em $\mathrm{g} \mathrm{ha}^{-1}$ ) utilizados foram trifloxysulfuron-sodium + ametryn $(27,77+1.097$ e $37+1.463)$, mesotrione $(120$ e 192), mesotrione + ametryn $(120+1.500)$, mesotrione + trifloxysulfuron-sodium + ametryn $[120+(27,77+1.097)]$, trifloxysulfuronsodium + ametryn + diuron + hexazinone $[(27,77+1.097)+(702+198)]$ e metribuzin $(1.920)$. Os herbicidas foram aplicados em pré-emergência das plantas daninhas sobre a palha de cana-de-açúcar; em pré-emergência das plantas daninhas sobre o solo e, em seguida, coberto com palha; e em pós-emergência das plantas daninhas, em jato dirigido nas entrelinhas da cana-de-açúcar. Eles sempre foram aplicados em pós-emergência da cultura, a qual apresentava aproximadamente $30 \mathrm{~cm}$ de altura. Os resultados permitiram concluir que a aplicação dos herbicidas sobre a palha de cana-de-açúcar e em pré-emergência das plantas daninhas alterou a eficácia do mesotrione a $120 \mathrm{~g}$, do trifloxysulfuron-sodium + ametryn $(27,77+1.097)$ e das misturas de mesotrine + ametryn e mesotrione + (trifloxysulfuron-sodium + ametryn). Os herbicidas metribuzin e (trifloxysulfuron-sodium + ametryn) + (diuron + hexazinone) foram eficazes no controle das espécies daninhas, independentemente da forma de aplicação. A espécie $B$. pilosa foi a mais suscetivel aos herbicidas e ao sistema de colheita cana-crua, ou seja, a palha sobre o solo inibiu o seu estabelecimento. Os herbicidas aplicados em jato dirigido na entrelinha da cana-de-açúcar, em pós-emergência, foram seletivos para a cultura.
\end{abstract}

Palavras-chave: Ipomoea quamoclit, Bidens pilosa, lixiviação, palha.

ABSTRACT - This work aimed to study the agronomic efficacy of herbicides applied in raw sugarcane harvest areas, to control Ipomea quamoclit and Bidens pilosa, on a commercial sugarcane farm with clayey textured soil in Araras-SP. The herbicides (in $\mathrm{g} \mathrm{ha}^{-1}$ ) were trifloxysulfuron-sodium + ametryn $(27,77+1,097$ and $37+1,463)$, mesotrione (120 and 192), mesotrione + ametryn $(120+$ 1,500), mesotrione + trifloxysulfuron-sodium + ametryn [120+(27,77 + 1,097)], trifloxysulfuronsodium + ametryn +diuron + hexazinone $[(27,77+1,097)+(702+198)]$ and metribuzin $(1,920)$ were applied in weed preemergence on the sugarcane straw; in weed preemergence on the soils ans afterwards covered with straw; and in weed postemergence, using a direct sprayer between the crop lines (approximately $30 \mathrm{~cm}$ high). Based on the results obtained, it was concluded that herbicide application on sugarcane straw and in weed preemergence altered the efficacy of mesotrione at $120 \mathrm{~g} \mathrm{ha}^{-1}$, of trifloxysulfuron sodium + ametryn $\left(27,77+1,097 \mathrm{~g} \mathrm{ha}^{-1}\right)$ and of the mixtures mesotrine + ametryn and mesotrione + (trifloxysulfuron sodium + ametryn); the herbicides metribuzin and (trifloxysulfuron sodium + ametryn) + (diuron + hexazinone) were effective in controlling the weeds, regardless of the mode of application. The weed species $\boldsymbol{B}$. pilosa was the most susceptible to the herbicides and to the raw sugarcane harvest system, i.e., straw on the soil inhibited its establishment. The herbicides applied using a direct sprayer between crop lines in postemergence were selective for the crop.

Keywords: I. quamoclit, Bidens pilosa, leaching, straw.

1 Recebido para publicação em 25.4.2008 e na forma revisada em 15.5.2008.

2 Professora Adjunta do Centro de Ciências Agrárias/UFSCar, Rodovia Anhanguera, km 174, 13600-247 Araras-SP, <pamonque@cca.ufscar.br>; ${ }^{3}$ Alunos de graduação do CCA/UFSCar; ${ }^{4}$ Pesquisadora do APTA/Pólo Regional da Alta Sorocabana. 


\section{INTRODUÇÃO}

Os impactos ambientais e sociais levaram à proibição da queimada em canaviais no Estado de São Paulo, segundo esquema de restrições legais progressivas até o ano de 2021, em áreas com possibilidade de mecanização total da colheita, e até 2031 para as demais áreas, de acordo com o Decreto no 47.700 de $11 / 3 / 2003$, que regulamenta a lei no 11.241 de 19/9/2002 (Timossi \& Durigan, 2006). Dessa forma, em áreas de colheita mecanizada da cana-crua, permanecerá sobre o solo uma espessa camada, que pode superar $20 \mathrm{tha}^{-1} \mathrm{de}$ palha, fato que influencia diretamente a ocorrência e o manejo de plantas daninhas (Velini \& Negrisoli, 2000).

A cobertura morta ocasiona mudanças químicas, físicas e biológicas no solo, podendo provocar seleção da comunidade infestante, suprimindo assim infestação de plantas daninhas normalmente consideradas importantes nos canaviais, como Digitaria horizontalis, Brachiaria plantaginea, Brachiaria decumbens e Panicum maximum (Velini et al., 2000; Medeiros, 2001; Gravena et al., 2004). No entanto, estão surgindo plantas-problema no sistema de cana-crua, como Euphorbia heterophylla e Ipomoea grandifolia (Martins et al., 1999).

A manutenção da palha sobre a superfície do solo pode, simultaneamente, reduzir o potencial de infestação das plantas daninhas e também dificultar o desempenho dos herbicidas, uma vez que a água da chuva se torna a principal responsável pelo transporte dos herbicidas até a superficie do solo (Maciel \& Velini, 2005; Simoni et al., 2006).

Para controle das plantas daninhas na cultura da cana-de-açúcar predomina o método químico, através de herbicidas aplicados em pré ou em pós-emergência das espécies. Segundo Freitas et al. (2004), o controle químico em áreas de cana-de-açúcar é uma prática bastante difundida em todo o Brasil. Entre as diversas opções de herbicidas registrados para a cultura da cana-de-açúcar, encontram-se os herbicidas inibidores da enzima acetolactato sintase (ALS), a exemplo do imazapic, imazapyr, trifloxysulfuronsodium, halosulfuron e flazasulfuron, e os herbicidas inibidores da fotossintese, como o ametryn, metribuzin, tebuthiuron, diuron e hexazinone. A maioria desses herbicidas apresenta ação em pré e em pós-emergência inicial, sendo recomendados no controle de mono e dicotiledôneas anuais e perenes de difícil controle, provendo períodos de controle efetivo nos solos superiores a 100 dias (Procópio et al., 2004).

Diversos autores têm realizado pesquisas quanto à lixiviação e ação dos herbicidas através da palha de cana-de-açúcar deixada sobre a superficie do solo. Cavenaghi et al. (2006a) verificaram que, com o aumento da quantidade de palha de cana sobre o solo, ocorreu diminuição da lixiviação do imazapic através da chuva, principalmente em $20 \mathrm{t} \mathrm{ha}^{-1}$ de palha. O mesmo resultado foi verificado com amicarbazone (Cavenaghi et al., 2007).

O herbicida trifloxysulfuron-sodium + ametryn aplicado na presença de até $10 \mathrm{t} \mathrm{ha}^{-1}$ de palha de cana-de-açúcar controlou satisfatoriamente as plantas daninhas Senna obtusifolia, Ipomoea nil, I. hederifolia e I. grandifolia. Quantidades maiores de palha reduziram a ação desse herbicida (Gravena et al., 2004). Monquero et al. (2007) observaram que 15 e $20 \mathrm{t} \mathrm{ha}^{-1}$ de palha causaram efeito negativo sobre a eficácia dos herbicidas trifloxysulfuron-sodium + ametryn, imazapic, imazapyr e diuron + hexazinone.

Em outro estudo, foi observado que os herbicidas sulfentrazone e imazapic foram eficazes no controle de Cyperus rotundus apenas quando não havia cobertura de solo com a palha da cana remanescente da colheita (Durigan et al., 2004). Azânia et al. (2004) constataram que $15 \mathrm{t} \mathrm{ha}^{-1}$ de palha promoveram a retenção do herbicida imazapic, especialmente sob períodos de pouca precipitação ou irrigação.

O presente trabalho teve como objetivo avaliar o comportamento de herbicidas residuais utilizados em áreas de cana-crua, aplicados em diferentes épocas, para o controle de Ipomoea quamoclit e Bidens pilosa.

\section{MATERIAL E MÉTODOS}

Os experimentos foram conduzidos em campo no município de Araras-SP, localizado na latitude de $22^{\circ} 21^{\prime} 25^{\prime \prime}$ sul e na longitude de 
$47^{\circ} 23^{\prime} 03^{\prime \prime}$ oeste, com altitude de $629 \mathrm{~m}$, em solo do tipo Latossolo Vermelho-Escuro, na safra de 2006/07. As demais características químicas e físicas do solo encontram-se na Tabela 1. O clima, pela classificação de Köppen, é do tipo Cwa, mesotérmico com verões quentes e úmidos e invernos secos. Os valores de temperatura média e precipitação pluvial referentes ao período de condução estão na Tabela 2.

Os experimentos foram conduzidos no sistema cana-soca após o segundo corte, sendo a variedade RB 92-8064, no espaçamento de $1,40 \mathrm{~m}$ entre as fileiras. O delineamento experimental utilizado foi o de bloco ao acaso, com 10 tratamentos e quatro repetições; na Tabela 3 encontram-se os tratamentos, doses e dados da formulação comercial. Os tratamentos foram aplicados em pré-emergência das plantas daninhas sobre a palha de canade-açúcar; em pré-emergência das plantas daninhas sobre o solo, em seguida coberto com palha; e em pós-emergência das plantas daninhas, em jato dirigido nas entrelinhas da cana-de-açúcar, com as plantas daninhas com o terceiro par de folhas definitivas e a cultura no estádio de $30 \mathrm{~cm}$ de altura. O tratamento em pré-emergência sobre o solo, seguido de cobertura de palha, objetivou simular a aplicação de herbicida realizada pela colhedora, em processo conjunto com a colheita mecanizada da cultura.

As parcelas foram constituídas nas dimensões de $6,0 \mathrm{~m}$ de comprimento e mantendo cinco linhas no espaçamento de 1,4 m. Posteriormente, as avaliações foram realizadas em área útil nas três linhas centrais, desprezandose $0,5 \mathrm{~m}$ de cada extremidade.

Os herbicidas foram aplicados com um pulverizador costal pressurizado a $\mathrm{CO}_{2}$, equipado com uma barra contendo duas pontas do tipo leque 11002 , espaçadas de $50 \mathrm{~cm}$ uma da outra e sob pressão de $2,5 \mathrm{kgf} \mathrm{cm}^{-2}$ e volume de $200 \mathrm{~L} \mathrm{ha}^{-1}$. As aplicações na modalidade em pré-emergência foram realizadas no dia 12/12/2006 e, em pós-emergência, em $15 / 1 / 2007$, estando a umidade relativa do ar, no início da aplicação, em 60 e $61 \%$, a temperatura do ar em 31 e $28{ }^{\circ} \mathrm{C}$, e a velocidade dos ventos, em $4,0 \mathrm{~km} \mathrm{~h}^{-1}$, respectivamente.

Para obtenção das plantas daninhas desejadas, foram semeadas as espécies Ipomoea quamoclit e Bidens pilosa em quatro subparcelas de $0,5 \mathrm{~m}^{2}$, na área útil de cada parcela. As sementes foram incorporadas ao solo a uma profundidade de 0 a $5 \mathrm{~cm}$, mantendo-se uma quantidade de 50 sementes viáveis por espécie.

As avaliações de eficácia das plantas daninhas foram realizadas visualmente aos 15, 30, 45, 60 e 90 dias após tratamento (DAT), por meio de uma escala percentual de notas de 0 a $100 \%$, em que 0 (zero) corresponde a nenhum controle e 100 a controle total.

Tabela 2 - Temperaturas máxima, mínima e média e precipitação em mm de chuvas nas 12 semanas durante a condução dos experimentos em pré e pós-emergência na cultura da canade-açúcar. Araras-SP, 2006/07

\begin{tabular}{|c|c|c|c|c|}
\hline \multirow{2}{*}{$\begin{array}{c}\text { Semana após } \\
\text { aplicação dos } \\
\text { herbicidas }\end{array}$} & \multicolumn{3}{|c|}{ Temperatura $\left({ }^{\circ} \mathrm{C}\right)$} & Chuva \\
\cline { 2 - 5 } & Tmáx & Tmín & Tméd & $(\mathrm{mm})$ \\
\hline $1^{\underline{\underline{a}}}$ & 33,2 & 17,6 & 25,4 & 16,2 \\
\hline $2^{\underline{\underline{a}}}$ & 32,0 & 19,2 & 25,6 & 42,8 \\
\hline $3^{\underline{\underline{a}}}$ & 31,0 & 18,4 & 24,7 & 40,0 \\
\hline $4^{\underline{\underline{a}}}$ & 28,8 & 19,2 & 24,0 & 179,0 \\
\hline $5^{\underline{\underline{a}}}$ & 32,4 & 20,4 & 26,4 & 37,0 \\
\hline $6^{\underline{\underline{a}}}$ & 30,0 & 18,4 & 24,2 & 142,0 \\
\hline $7^{\mathrm{a}}$ & 30,6 & 17,4 & 24,0 & 52,4 \\
\hline $8^{\underline{\underline{a}}}$ & 33,3 & 18,0 & 25,6 & 19,6 \\
\hline $9^{\underline{\underline{a}}}$ & 31,6 & 16,8 & 24,2 & 123,0 \\
\hline $1^{\underline{\underline{a}}}$ & 33,8 & 14,8 & 24,3 & 14,8 \\
\hline $11^{\underline{\underline{a}}}$ & 32,6 & 18,2 & 25,4 & 13,2 \\
\hline $12^{\underline{\underline{a}}}$ & 28,4 & 18,2 & 23,3 & 47,2 \\
\hline
\end{tabular}

Tabela 1 - Resultados da análise química do solo, dos experimentos conduzidos em pré e pós-emergência na cultura da cana-de-açúcar. Araras,SP, 2006/07

\begin{tabular}{|c|c|c|c|c|c|c|c|c|c|c|c|c|c|}
\hline \multirow{2}{*}{ Amostra } & $\mathrm{pH}$ & $\mathrm{MO}$ & $\mathrm{P}$ & $\mathrm{K}$ & $\mathrm{Ca}$ & $\mathrm{Mg}$ & $\mathrm{Al}$ & $\mathrm{SB}$ & $\mathrm{CTC}$ & $\mathrm{V}$ & Argila & Silte & Areia \\
\cline { 2 - 12 } & $\left(\mathrm{CaCl}_{2}{ }^{)}\right.$ & $\left(\mathrm{g} \mathrm{dm}^{-3}\right)$ & $\left(\mathrm{mg} \mathrm{dm}^{-3}\right)$ & \multicolumn{6}{|c|}{$\left(\mathrm{mmol}_{\mathrm{c}} \mathrm{dm}^{-3}\right)$} & \multicolumn{3}{|c|}{$\left(\mathrm{g} \mathrm{kg}^{-1}\right)$} \\
\hline $\mathrm{LVd}$ & 5,3 & 22 & 12 & 2,3 & 28 & 11 & - & 41,3 & 65,3 & 63 & 530 & 320 & 150 \\
\hline
\end{tabular}


Tabela 3 - Tratamentos, nome comercial e dose do igrediente ativo (i.a.) e produto comercial (p.c.) utilizados nos experimentos em pré e pós-emergência na cultura da cana-de-açúcar. Araras-SP, 2006/07

\begin{tabular}{|l|c|c|c|}
\hline \multicolumn{1}{|c|}{ Tratamento } & Nome comercial & $\begin{array}{c}\text { Dose } \\
\left(\mathrm{g} \mathrm{ou} \mathrm{mL} \mathrm{i.a} \mathrm{ha}^{-1}\right)\end{array}$ & $\begin{array}{c}\text { Dose } \\
(\mathrm{g} \mathrm{ou} \mathrm{mL} \mathrm{pc} \mathrm{ha}\end{array}$ \\
\hline 1-trifloxysufuron-sodium + ametryn & Krismat & $27,77+1097$ & 1500 \\
\hline 2-trifloxysufuron-sodium + ametryn & Krismat & $37+1463$ & 2000 \\
\hline 3-mesotrione & Callisto & 120 & 250 \\
\hline 4- mesotrione & Callisto & 192 & 400 \\
\hline 5- mesotrione + ametryn & Callisto + Gesapax & $120+1500$ & $250+3000$ \\
\hline 6-mesotrione + (trifloxysufuron-sodium + ametryn) & Callisto + Krismat & $120+(27,77+1097)$ & $250+1500$ \\
\hline 7-metribuzin & Sencor & 1920 & 4000 \\
\hline 8-(trifloxysulfuron-sodium + ametryn) + (diuron + hexazinone) & Krismat + Velpar & $(27,77+1097)+(702+198)$ & $1500+1500$ \\
\hline
\end{tabular}

Todos os tratamentos foram aplicados em pré e pós-emergência. Em condições de pós-emergência, adicionou-se adjuvante Agral $0,2 \%$ nos tratamentos 1,2 e 8 e o Assist $0,5 \%$ nos tratamentos 3, 4, 5, 6 e 7 .

As avaliações de fitotoxicidade às plantas da cultura foram realizadas visualmente aos 15,30 e 60 DAT, através de uma escala percentual de notas de 0 a $100 \%$, em que 0 (zero) corresponde a nenhuma injúria e 100 à morte completa.

Após obtenção dos dados, estes foram submetidos à análise de variância, e os coeficientes das equações de regressão, obtidos pelo programa Sigmaplot, utilizando o teste de Tukey a 5\% de probabilidade.

\section{RESULTADOS E DISCUSSÃO}

Resultados da porcentagem de controle de I. quamoclit quando os herbicidas foram aplicados diretamente ao solo podem ser observados na Figura 1 e Tabela 4. Com o herbicida mesotrione isolado ou em mistura com ametryn e com (trifloxysulfuron-sodium + ametryn), assim como com o metribuzin e (trifloxysulfuron-sodium + ametryn) + (diuron + hexazinone), obteve-se controle de $80 \%$ da espécie. Carvalho et al. (2006) observaram efeito sinergístico do mesotrione com os herbicidas ametryn e metribuzin no controle de Brachiaria decumbens, B. pilosa e $E$. heterophylla, sendo o efeito mais pronunciado na mistura com ametryn.

Quando os herbicidas foram aplicados sobre a palha da cana-de-açúcar, a tendência foi a mesma, ou seja, controle superior a $80 \%$ pelos herbicidas mesotrione na maior dose, mesotrione + ametryn, metribuzin e (trifloxysulfuron-sodium + ametryn) + (diuron + hexazinone) (Figura 1). Em relação ao metribuzin, Banks \& Robinson (1982) verificaram que menos de $1 \%$ desse herbicida alcançou o solo antes da irrigação em áreas com cobertura vegetal com palha de trigo $\left(9 \mathrm{t} \mathrm{ha}^{-1}\right)$. Por outro lado, quando as parcelas foram irrigadas logo após a aplicação, observouse que $56 \%$ do metribuzin atingiu o solo.

O controle eficaz da pomoea quamoclit é importante, pois algumas espécies do gênero Ipomoea tendem a mostrar-se de dificil controle nas áreas de cana-de-açúcar conduzidas no sistema de colheita mecanizada. Azânia et al. (2002) afirmaram que, com até $15 \mathrm{t} \mathrm{ha}^{-1}$ de palha, a emergência de I. grandifolia, I. hederifolia e I. nil não foi significativamente alterada. Tem sido constatada redução nas populações dessas plantas daninhas somente na presença de $20 \mathrm{t} \mathrm{ha}^{-1}$. Quanto às espécies Ipomoea quamoclit e Merremia cissoides, o efeito negativo da palha de cana-de-açúcar foi observado nas quantidades de 15 e 20 t ha $^{-1}$, mas não inferior a $10 \mathrm{t} \mathrm{ha}^{-1}$.

Em pós-emergência, os piores resultados, quando aplicados nas menores doses, foram obtidos com os tratamentos trifloxysulfuronsodium + ametryn $(75 \%)$ e o mesotrione $(80 \%)$, índice este considerado o mínimo aceitável, conforme pode ser observado na Figura 1 e na Tabela 4. Os demais tratamentos promoveram controles superiores, a exemplo do metribuzin, com $88 \%$, (trifloxysulfuron-sodium+ametryn)+ (hexazionone+diuron), mesotrione na dose maior, trifloxysulfuron-sodium+ametryn na dose maior, com indices de controle em torno de $95 \%$, e o controle máximo, para mesotrine + ametryn e mesotrione associado ao trifloxysullfuron-sodium + ametryn. 
Na Figura 2 e Tabela 4 encontram-se os resultados de eficácia no controle para a espécie Bidens pilosa nas três modalidades de aplicação. Verifica-se que todos os herbicidas utilizados em pré-emergência promoveram indices de controle superiores a 90\%, independentemente da forma de aplicação. A espécie B. pilosa mostrou ser mais suscetivel a todos os tratamentos e também à presença da palha, já que se verificou baixa emergência dessa espécie na testemunha com palha sem herbicida. Medina-Melendez (1990) observou que a palha da cana-de-açúcar inibiu totalmente a germinação de $B$. pilosa e de outras espécies por efeito físico e/ou alelopático. Em pós-emergência, os tratamentos trifloxysulfuron-sodium
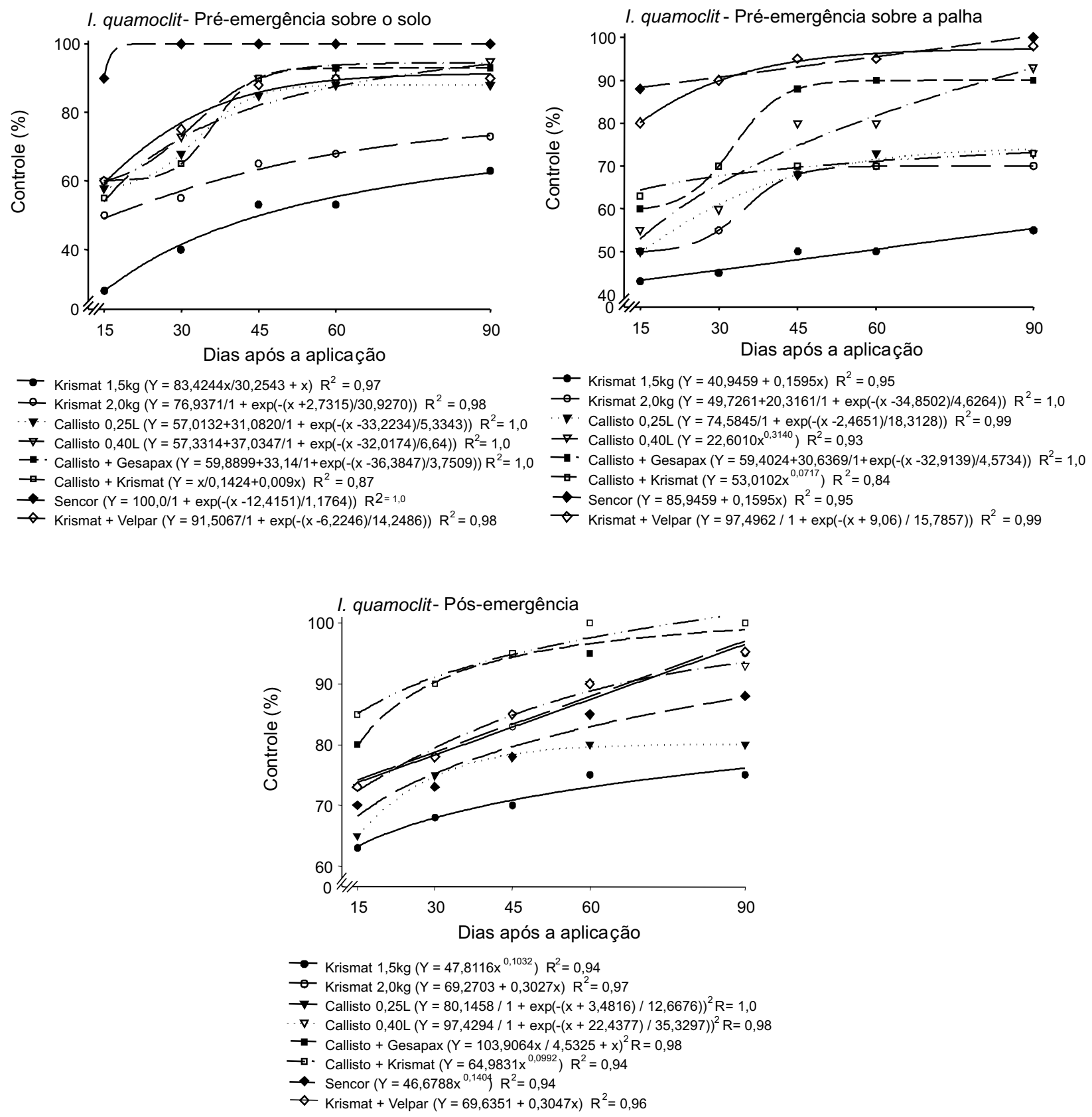

Figura 1 - Porcentagem de controle da planta daninha Ipomoea quamoclit aos 15, 30, 45, 60 e 90 DAT, com os herbicidas aplicados em pré-emergência sobre o solo, sobre a palha e em pós-emergência. 
+ ametryn e mesotrione, aplicados nas menores doses, proporcionaram controle de $78 \%$. Todos os demais tratamentos promoveram indice de controle maior ou igual a $90 \%$.

Com relação à fitotoxicidade, como foram observados sintomas apenas na primeira avaliação, não se incluiu tabela no presente trabalho. A avaliação visual de fitotoxicidade evidenciou sintomas, como clorose foliar, nas maiores doses utilizadas dos herbicidas trifloxysulfuron-sodium + ametryn $(20 \%)$ e mesotrione $(30 \%)$. Esses sintomas ocorreram apenas aos 15 DAT; posteriormente, as plantas da cana-de-açúcar se recuperaram e não apresentaram efeitos visuais causados pela ação dos herbicidas. Aos 90 DAT, nenhum tratamento apresentava sintomas visuais de fitotoxicidade nas plantas de cana-de-açúcar. Assim, pode-se concluir que os herbicidas
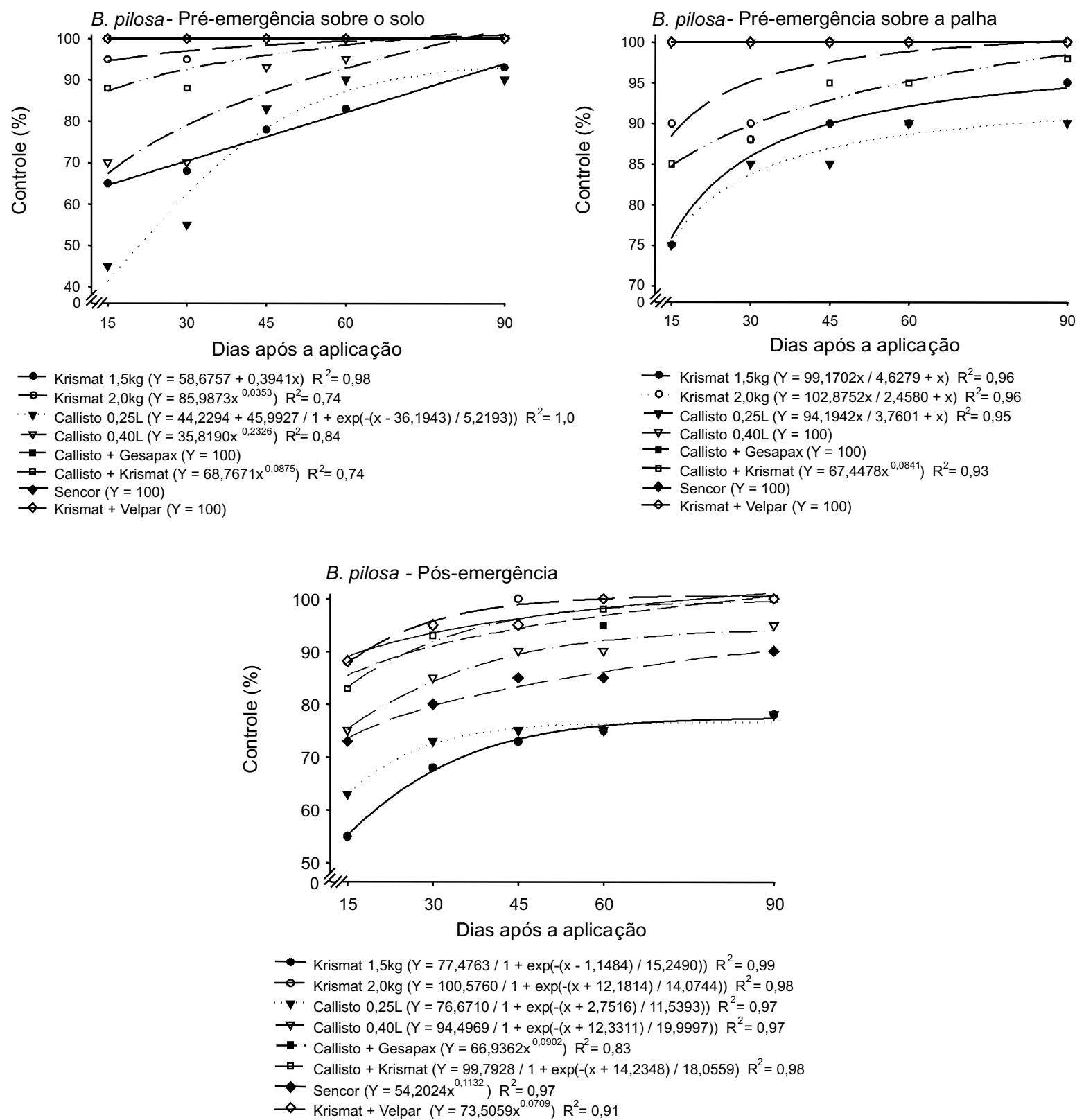

Figura 2 - Porcentagem de controle da planta daninha Bidens pilosa aos 15, 30, 45 e 60 DAT, com os herbicidas aplicados em pré-emergência sobre o solo, sobre a palha e em pós-emergência. 
Tabela 4 - Porcentagem de controle de B. pilosa e I. quamoclit aos 90 DAT, por diferentes herbicidas e modos de aplicação

\begin{tabular}{|c|c|c|}
\hline Tratamento & $\mathrm{BIDP}^{1 /}$ & IQUA $^{2 /}$ \\
\hline 1- trifloxysufluron-sodium + ametryn & $93,0 \mathrm{aA}$ & $63,0 \mathrm{cB}$ \\
\hline 2- trifloxysufluron-sodium + ametryn & $100,0 \mathrm{aA}$ & $73,0 \mathrm{bcB}$ \\
\hline 3- mesotrione & $90,0 \mathrm{aA}$ & $88,0 \mathrm{abA}$ \\
\hline 4- mesotrione & $100,0 \mathrm{aA}$ & $95,0 \mathrm{abA}$ \\
\hline 5- mesotrione + ametryn & $100,0 \mathrm{aA}$ & $93,0 \mathrm{bB}$ \\
\hline 6- mesotrione $+($ trifloxysufluron -sodium + ametryn $)$ & $100,0 \mathrm{aA}$ & $90,0 \mathrm{bB}$ \\
\hline 7- metribuzin & $100,0 \mathrm{aA}$ & $100,0 \mathrm{aA}$ \\
\hline 8 - (trifloxysufluron-sodium + ametryn $)+($ diuron + hexazinone $)$ & $100,0 \mathrm{aA}$ & $90,0 \mathrm{bB}$ \\
\hline DMS 5\% & \multicolumn{2}{|c|}{6,07} \\
\hline Tratamentos & BIDP & IQUA \\
\hline 1- trifloxysufluron-sodium + ametryn & $95,0 \mathrm{aA}$ & $55,0 \mathrm{~dB}$ \\
\hline 2- trifloxysufluron-sodium + ametryn & $100,0 \mathrm{aA}$ & $70,0 \mathrm{cB}$ \\
\hline 3- mesotrione & $100,0 \mathrm{aA}$ & $73,0 \mathrm{cB}$ \\
\hline 4- mesotrione & $100,0 \mathrm{aA}$ & $93,0 \mathrm{bB}$ \\
\hline 5- mesotrione + ametryn & $100,0 \mathrm{aA}$ & $90,0 \mathrm{bB}$ \\
\hline 6- mesotrione + (trifloxysufluron-sodium + ametryn $)$ & $98,00 \mathrm{aA}$ & $73,0 \mathrm{cB}$ \\
\hline 7- metribuzin & $100,0 \mathrm{aA}$ & $100,0 \mathrm{aA}$ \\
\hline 8- (trifloxysufluron-sodium + ametryn $)+($ diuron + hexazinone $)$ & $100,0 \mathrm{aA}$ & $98,0 \mathrm{aA}$ \\
\hline DMS 5\% & \multicolumn{2}{|c|}{$\frac{1}{4,75}$} \\
\hline Tratamentos & BIDP & IQUA \\
\hline 1- trifloxysufluron-sodium + ametryn & $78,0 \mathrm{bA}$ & $75,0 \mathrm{cdA}$ \\
\hline 2- trifloxysufluron-sodium + ametryn & $100,0 \mathrm{aA}$ & $95,0 \mathrm{abAB}$ \\
\hline 3- mesotrione & $78,0 \mathrm{bA}$ & $80,0 \mathrm{cA}$ \\
\hline 4- mesotrione & $95,0 \mathrm{abA}$ & $93,0 \mathrm{bA}$ \\
\hline 5- mesotrione + ametryn & $100,0 \mathrm{aA}$ & $100,0 \mathrm{aA}$ \\
\hline 6- mesotrione+(trifloxysufluron-sodium + ametryn $)$ & $100,00 \mathrm{aA}$ & $100,0 \mathrm{aA}$ \\
\hline 7- metribuzin & $90,0 \mathrm{abA}$ & $88,0 \mathrm{bcA}$ \\
\hline 8- (trifloxysufluron-sodium + ametryn) + (diuron + hexazinone $)$ & $100,0 \mathrm{aA}$ & $95,0 \mathrm{abAB}$ \\
\hline DMS 5\% & \multicolumn{2}{|l|}{5,09} \\
\hline
\end{tabular}

${ }^{1 /}$ B. pilosa $\mathrm{e}^{2 /} I$. quamoclit. Médias seguidas por letras iguais, maiúsculas nas linhas e minúsculas nas colunas, não diferem significativamente entre si pelo teste de Tukey a $5 \%$ de probabilidade.

utilizados foram seletivos para a cana-deaçúcar, nas condições em que foi conduzida a pesquisa.

Em trabalho anterior, Lossaco et al. (2006) constataram que as associações de mesotrione com diuron + hexazinone e com trifloxysulfuron-sodium + ametryn foram eficientes no controle de Digitaria horizontalis e Brachiaria decumbens e seletivas para a cultura da cana-de-açúcar. Ferreira et al. (2005) verificaram que a variedade RB 92-8064 apresenta boa tolerância ao trifloxysulfuronsodium + ametryn $\left(18,5+731,5 \mathrm{~g} \mathrm{~kg}^{-1}\right)$.

Nas condições em que foi conduzido o experimento, pode-se concluir que os herbicidas aplicados em jato dirigido nas entrelinhas da cana-de-açúcar foram seletivos à cultura e podem ser mais uma opção de manejo da cultura. O herbicida trifloxysulfuron-sodium + ametryn aplicado na menor dose foi o tratamento menos eficiente no controle da espécie daninha
I. quamoclit, independentemente da forma de aplicação. A aplicação dos herbicidas sobre a palha de cana-de-açúcar em pré-emergência das plantas daninhas alterou a eficácia do mesotrione e trifloxysulfuron-sodium + ametryn aplicados na menor dose e das misturas mesotrine + ametryn e mesotrione + (trifloxysulfuron-sodium + ametryn).

Os herbicidas metribuzin e (trifloxysulfuronsodium + ametryn) + (diuron + hexazinone $)$ foram eficazes no controle de todas as espécies daninhas, independentemente da forma de aplicação, e B. pilosa foi a espécie mais suscetivel aos herbicidas e ao sistema de colheita cana-crua, ou seja, a palha sobre o solo inibiu o seu estabelecimento.

\section{LITERATURA CITADA}

ASSOCIACION LATINOAMERICANA DE MALEZAS ALAM. Recomendaciones sobre unificación de los sistemas de evaluación em ensayos de control de malezas. ALAM, v. 1, p. $35-38,1974$. 
AZÂNIA, C. A. M. et al. Seletividade do imazapic para dois cultivares de amendoim (Arachis hypogaea) cultivados na ausência e na presença de palha de cana-de-açúcar. Planta Daninha, v. 22, n. 1, p. 145-150, 2004

AZÂNIA, A. A. P. M. et al. Interferência da palha de cana-deaçúcar (Saccharum spp.) na emergência de espécies de plantas daninhas da família Convolvulaceae. Planta Daninha, v. 20, n. 2, p. 207-212, 2002.

BANKS, P. A.; ROBINSON, E. L. The influence of straw mulch on the soil reception and persistence of metribuzin. Weed Sci., v. 30, n. 2, p. 164-168, 1982.

CARVALHO, F. T. et al. Eficácia do herbicida mesotrione em parceria com ametryn e metribuzin no controle pós-emergente de dez espécies daninhas em cana-de-açúcar. In: CONGRESSO BRASILEIRO DA CIÊNCIA DAS PLANTAS DANINHAS, 25., 2006, Brasília. Convivendo com as plantas daninhas. Resumos... Brasília: SBCPD/UNB/ Embrapa Cerrados, 2006. v. 25.

CAVENAGHI, A. L. et al. Dinâmica do herbicida imazapic aplicado sobre a palha de cana-de-açúcar. In: CONGRESSO BRASILEIRO DA CIÊNCIA DAS PLANTAS DANINHAS, 25, 2006 Brasília. Resumos... Brasília: SBCPD; UNB; Embrapa Cerrados, 2006. p. 360.

CAVENAGHI, A. L. et al. Dinâmica do herbicida imazapic aplicado sobre a palha de cana-de-açúcar. Planta Daninha, v. 25 , n. 4 , p. $831-837,2007$

DURIGAN, J. C.; TIMOSSI, P. C.; LEITE, G. J. Controle químico da tiririca (Cyperus rotundus), com e sem cobertura do solo pela palha de cana-de-açúcar. Planta Daninha, v. 22, n. 1, p. 127-135, 2004.

FERREIRA, E. A. et al. Sensitivity of sugarcane cultivars to trifloxysulfuron sodium + ametryn mixture. Planta Daninha v. 23, n. 1, p. 93-99, 2005.

FREITAS, S. P. et al. Controle químico de Rottboelia exaltata em cana-de-açúcar. Planta Daninha, v. 22, n. 3, p. 461-466, 2004.

GRAVENA, R. et al. Controle de plantas daninhas através da palha de cana-de-açúcar associada à mistura dos herbicidas trifloxysulfuron sodium + ametryn. Planta Daninha, v. 22, n. 3, p. 419-427, 2004.

LOSSACO, P. H. et al. Eficácia e seletividade de mesotrione na mistura em tanque com herbicidas residuais no controle de Digitaria horizontalis e Brachiaria decumbens em cana-deaçúcar soca. In: CONGRESSO BRASILEIRO DA CIÊNCIA DAS PLANTAS DANINHAS, 25., 2006. Resumos... Brasília: SBCPD/ UNB/ Embrapa Cerrados, 2006. p. 275.
MACIEL, C. D. G.; VELINI, E. D. Simulação do caminhamento da água da chuva e herbicidas em palhadas utilizadas em sistemas de plantio direto. Planta Daninha, v. 23, n. 3 , p. $471-481,2005$

MARTINS, D. et al. Emergência em campo de dicotiledôneas infestantes em solo coberto com palha de cana-de-açúcar.

Planta Daninha, v. 17, n. 1, p. 151-161, 1999.

MEDEIROS, D. Efeitos da palha de cana-de-açúcar (Saccharum spp.) sobre o manejo de plantas daninhas e dinâmica do banco de sementes. 2001. 126 f. Dissertação (Mestrado em Fitotecnia) - Escola Superior de Agricultura "Luiz de Queiroz", Piracicaba, 2001.

MEDINA-MELENDEZ, J. A. Efeito da cobertura do solo no controle das plantas daninhas na cultura do pepino. 1990. 104 f. Dissertação (Mestrado em Fitotecnia) Escola Superior de Agricultura "Luiz de Queiroz", Piracicaba, 2001.

MONQUERO, P. A. et al. Eficácia de herbicidas em diferentes quantidades de palha de cana-de-açúcar no controle de Euphorbia heterophylla. Planta Daninha, v. 25, n. 3, p. 613-619, 2007.

PROCÓPIO, S. O.; SILVA, A. A.; VARGAS, L. Manejo e controle de plantas daninhas em cana-de-açúcar. In: VARGAS, L.; ROMAN, E. S. (Eds.). Manual de manejo e controle de plantas daninhas. Bento Gonçalves: Embrapa Uva e Vinho, 2004. p. 397-452.

SIMONI, F. et al. Eficácia de imazapic e sulfentrazone sobre Cyperus rotundus em diferentes condições de chuva e palha de cana-de-açúcar. Planta Daninha, v. 24, n. 4, p. 769-778, 2006.

TIMOSSI, P. C.; DURIGAN, J. C. Manejo de convolvuláceas em dois cultivares de soja semeada diretamente sob palha residual de cana crua. Planta Daninha, v. 24, n. 1, p. 91-98, 2006.

VELINI, E. D. et al. Efeito da palha da cana-de-açúcar sobre a germinação das principais espécies de plantas daninhas gramíneas desta cultura. In: CONGRESSO BRASILEIRO DA CIÊNCIA DAS PLANTAS DANINHAS, 22., 2000, Foz do Iguaçu. Resumos... Londrina: SBCPD, 2000. p. 15

VELINI, E. D.; NEGRISOLI, E. Controle de plantas daninhas em cana crua. In: CONGRESSO BRASILEIRO DA CIENNCIA DAS PLANTAS DANINHAS, 22., 2000, Foz do Iguaçu.

Palestras... Foz do Iguaçu: 2000. p. 148-164. 